Supporting Information

\title{
Membrane Activation: Selective Vesicle Fusion via Small Molecule Recognition
}

Yun Gong, Yumei Luo and Dennis Bong*

Department of Chemistry, The Ohio State University, Columbus, Ohio 43210. 


\section{A. SYNTHESIS}

Synthetic Schemes. (Based on known synthesis procedures as referenced)

\section{Scheme 1.}
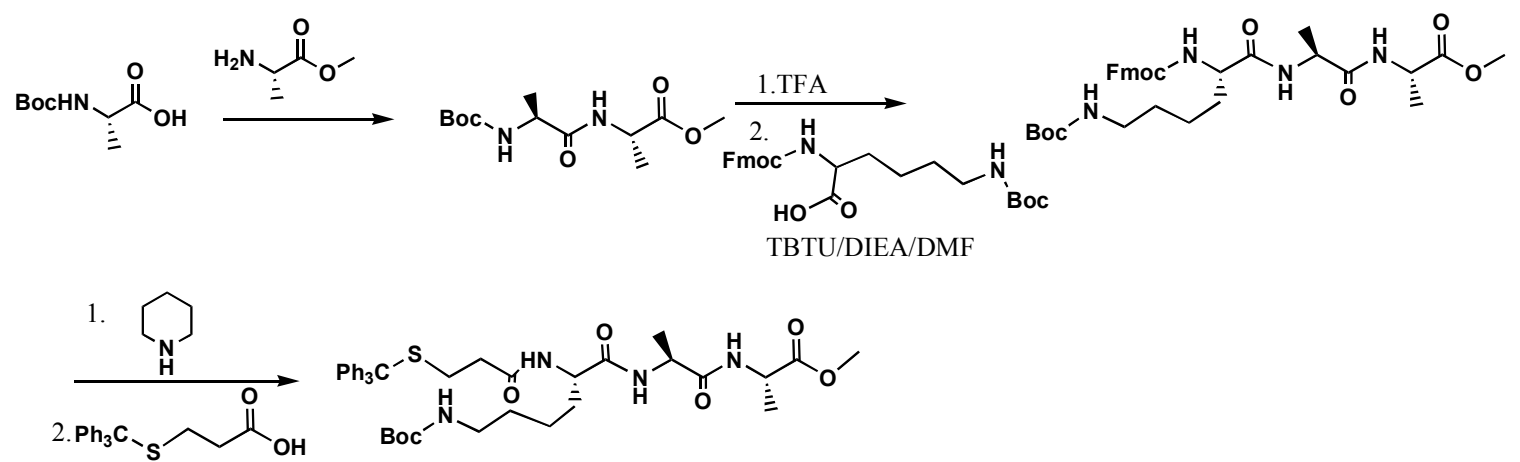

TBTU/DIEA/DMF
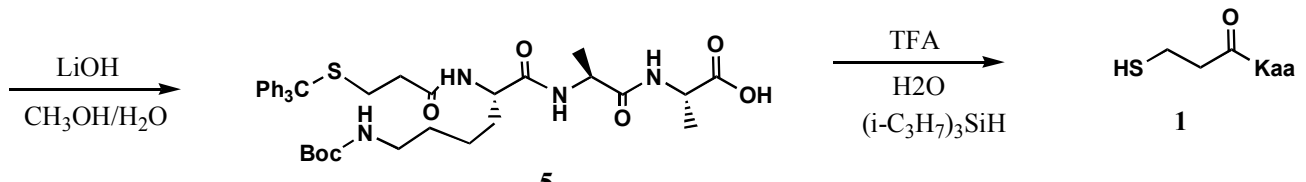

5
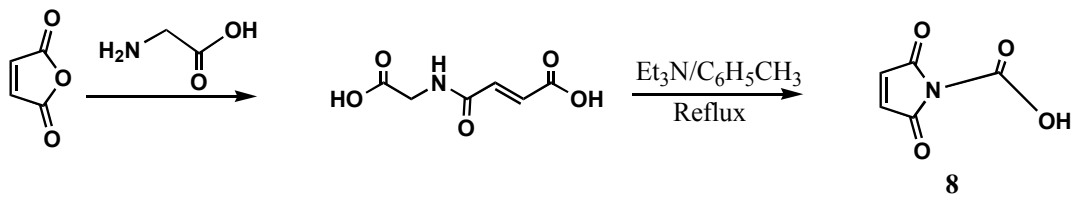

\section{Scheme 1 synthesis from:}

Rich, D.I H.; Gesellchen, P. D.; Tong A.; Buckner, C. K., Journal of Medicinal

Chemistry 1975, 18, (10), 1004-10 
Scheme 2. Linker synthesis. (See text below)

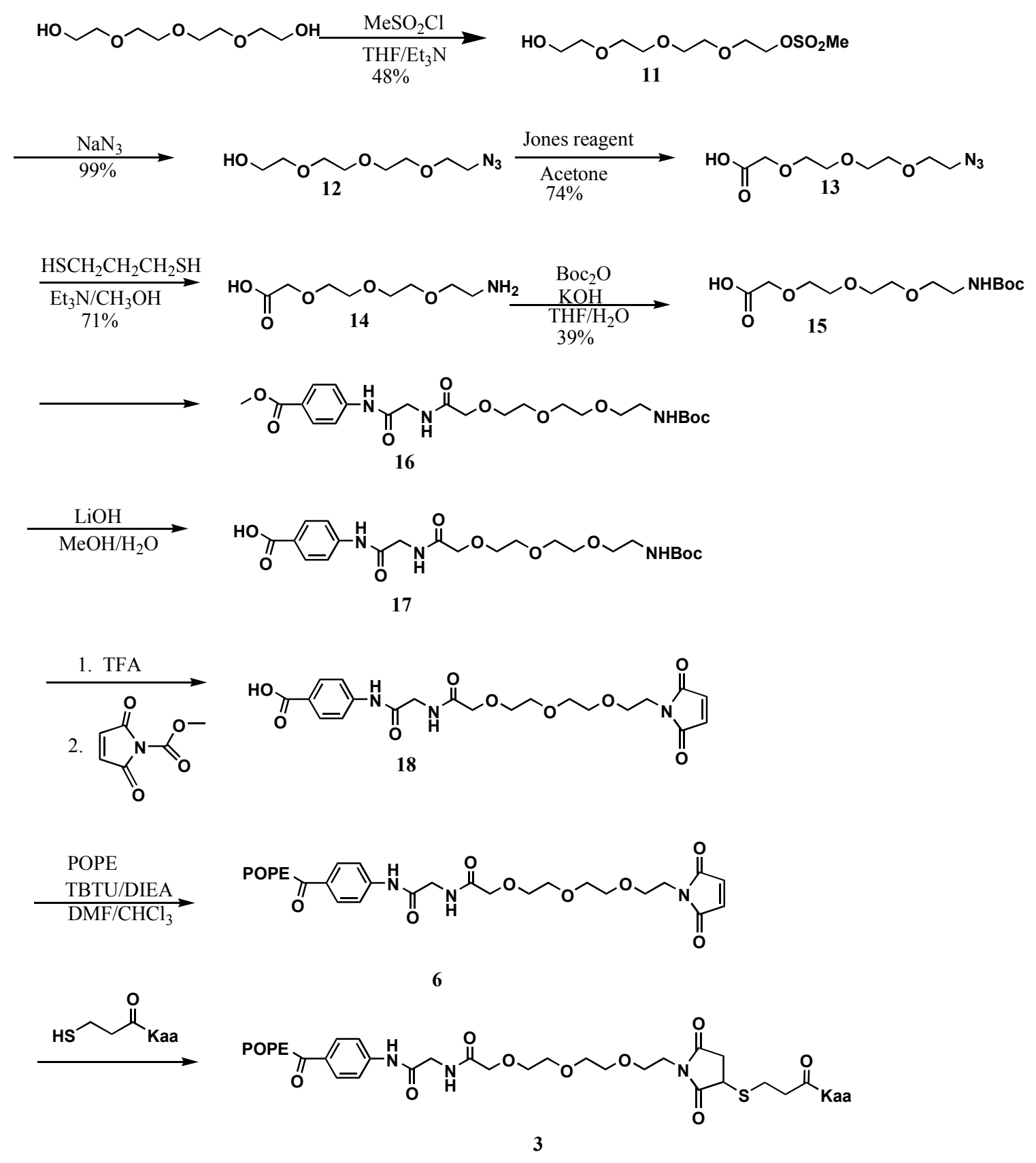

\section{Synthetic Procedures:}

1-(1,1-dimethylethyl 8,11-Trioxa-2-azatridecanedioate (13) was synthesized following literature procedures. ${ }^{1-5}$ Mono mesylation of tetra(ethyleneglycol) and a subsequent reaction with sodium azide produced $\omega$-azide alcohol $\mathbf{1 2}$, which was oxidized with Jones 
reagent to carboxylic acid $\mathbf{1 3}$. Reduction of $\mathbf{1 3}$ followed by protection of the resulting primary amino group in $\mathbf{1 4}$ produced N-Boc-amino acid $\mathbf{1 5 .}$

Preparation of compound 16. N-Boc-amino acid 15 (307.0 mg, 1.mmol), TBTU (321.0 $\mathrm{mg}, 1 \mathrm{mmol})$ and DIEA (258mg, $2 \mathrm{mmol})$ were dissolved in the DMF (5 mL), after stirred for $30 \mathrm{~min}$. The methyl 4-[(aminoacetyl) amino] benzoate (1mmol) DMF (5mL) solution was added. After the mixture was stirred at room temperature for $3 \mathrm{~h}$, the solvent was removed under reduce pressure. The residue was purified with flash chromatography column (methanol/methelene chloride as eluting solvent), gave the compound $\mathbf{1 6} 410.0$ $\mathrm{mg}$ in $82 \%$ yield. MS calcd 497 , found $520\left(\mathrm{M}+\mathrm{Na}^{+}\right) ;{ }^{1} \mathrm{HNMR}\left(\mathrm{CDCl}_{3}, \delta\right) 9.21(1 \mathrm{H}, \mathrm{s})$, $7.86(2 \mathrm{H}, \mathrm{d}, \mathrm{J}=11.2 \mathrm{~Hz}), 7.53(2 \mathrm{H}, \mathrm{d}, \mathrm{J}=11.2 \mathrm{~Hz}), 5.12(1 \mathrm{H}, \mathrm{br}), 4.07(2 \mathrm{H}, \mathrm{d}, \mathrm{j}=6.0 \mathrm{~Hz})$, $3.77(\mathrm{~s}, 3 \mathrm{H}), 3.64(\mathrm{~m}, 4 \mathrm{H}), 3.41(2 \mathrm{H}, \mathrm{t}, \mathrm{J}=5.3 \mathrm{~Hz}), 3.00(1 \mathrm{H}, \mathrm{m}), 1.34(\mathrm{~s}, 9 \mathrm{H})$

Preparation of Compound 17 The compound16 (110 mg) was dissolved in the water/methanol (1:1, $3.0 \mathrm{~mL})$, lithium hydroxide (4mmol) was added, after stirred for 30 min, the mixture was acidified with $\mathrm{HCl}(1 \mathrm{M})$, extracted with ethyl acetate, combined organic layer, dried with anhydrous sodium sulfate. The solvent was removed and the residue was purified and given $65 \mathrm{mg}$ in $60 \%$ yield. ${ }^{1} \mathrm{HNMR}\left(\mathrm{CD}_{3} \mathrm{OD}, \delta\right) 7.89(2 \mathrm{H}, \mathrm{d}$, $\mathrm{J}=11.3 \mathrm{~Hz}), 7.60(2 \mathrm{H}, \mathrm{d}, \mathrm{J}=11.3 \mathrm{~Hz}), 4.05(4 \mathrm{H}, \mathrm{m}), 3.65-3.50(6 \mathrm{H}, \mathrm{m}), 3.43(2 \mathrm{H}, \mathrm{t}, \mathrm{J}=5.7$ $\mathrm{Hz}), 3.23(2 \mathrm{H}, \mathrm{m}), 3.13(2 \mathrm{H}, \mathrm{t}, \mathrm{J}=8.23 \mathrm{~Hz}), 1.43(9 \mathrm{H}, \mathrm{s})$; MS Calcd. 483, found 506 $\left(\mathrm{M}+\mathrm{Na}^{+}\right)$

Preparation of Compound 18. Compound 17 (113 mg, $0.23 \mathrm{mmol})$ was dissolved in methylenechloride $(1 \mathrm{~mL})$, and TFA $(1 \mathrm{~mL})$ was added. The reaction was monitored by TLC.After the reaction is complete, the solvent was removed and the residue was dissolved in the water and saturated sodium bicarbonate aqueous solution $(1.5 \mathrm{~mL})$ was 
added. The $\mathrm{N}$-methoxycarbonylmaleimide $(47 \mathrm{mg}, 0,30 \mathrm{mmol}$ ) was added, the mixture was stirred at room temperature for $1 \mathrm{~h}$, neutralized with $\mathrm{HCl}(1 \mathrm{M})$ and extracted with ethyl acetate, dried with anhydrous sodium sulfate. The solvent was removed, and purified flash chromatography column and gave the compound $1860 \mathrm{mg}$ in 52\% yield. ${ }^{1} \mathrm{H}$ NMR $\left(\mathrm{CD}_{3} \mathrm{OD}, \delta\right) 7.89(2 \mathrm{H}, \mathrm{d}, \mathrm{J}=11.5 \mathrm{~Hz}), 7.60(2 \mathrm{H}, \mathrm{d}, \mathrm{J}=11.5 \mathrm{~Hz}), 6.69(2 \mathrm{H}, \mathrm{s}), 4.05$ $(4 \mathrm{H}, \mathrm{m}), 3.65(8 \mathrm{H}, \mathrm{m}), 3.23(6 \mathrm{H}, \mathrm{m}) ;$ MS Calcd. 477, found $500\left(\mathrm{M}+\mathrm{Na}^{+}\right)$. Preparation of compound 6, Compound 18 (27.8 mg), TBTU (19.3 mg) and DIEA (20 $\mathrm{mg}$ ) were dissolved in the DMF $(3 \mathrm{~mL})$ and the mixture was stirred at room temperature for $30 \mathrm{~min}$. The POPE (43, $\mathrm{mg})$ in chloroform was added. The reaction mixture was stirred overnight. The solvent was removed, and the residue was purified with flash chromatography column and gave the compound $650 \mathrm{mg}$ in 74\%yield. ${ }^{1} \mathrm{HNMR}$ see Figure S15, CNMR see Figure S16.

Preparation of compound 3. Compound $1(13.6 \mu \mathrm{mol})$ in methanol $(0.5 \mathrm{~mL})$, compound 6 ( $8.0 \mathrm{mg}, 6.8 \mu \mathrm{mol})$ was dissolved in methanol $(1 \mathrm{~mL})$, and DIEA $(3 \mathrm{mg})$ was added. After reaction was complete, the solvent was removed. The residue was purified with flash chromatography column and gave the compound $35.0 \mathrm{mg}$ in 47\%yield. MS (see Figure S8. ESI of 3, M.W. 1539.)

\section{References for Scheme 2}

1. Frisch, B.; Boeckler, C.; Schuber, F., Bioconjugate Chemistry 1996, 2, (2), 180-6

2. Jeong, S. W.; O'Brien, D. F., Journal of Organic Chemistry 2001, 66, (14), 47994802

3. Lebeau, L.; Oudet, P.; Mioskowski, C., Helvetica Chimica Acta 1991, 74, (8), 16971706

4. Nicolaou, K. C.; Mitchell, H. J.; Jain, Nareshkumar F.; Winssinger, N.; Huges, R.; Bando, T., Angwandte Chemie, International Edition 1999, 38, (1/2), 240-244

5. Schoenmakers, R. G., Journal of Controlled Release, 2004, 95, (2), 291-300 


\section{Scheme 3. ${ }^{1-4}$}
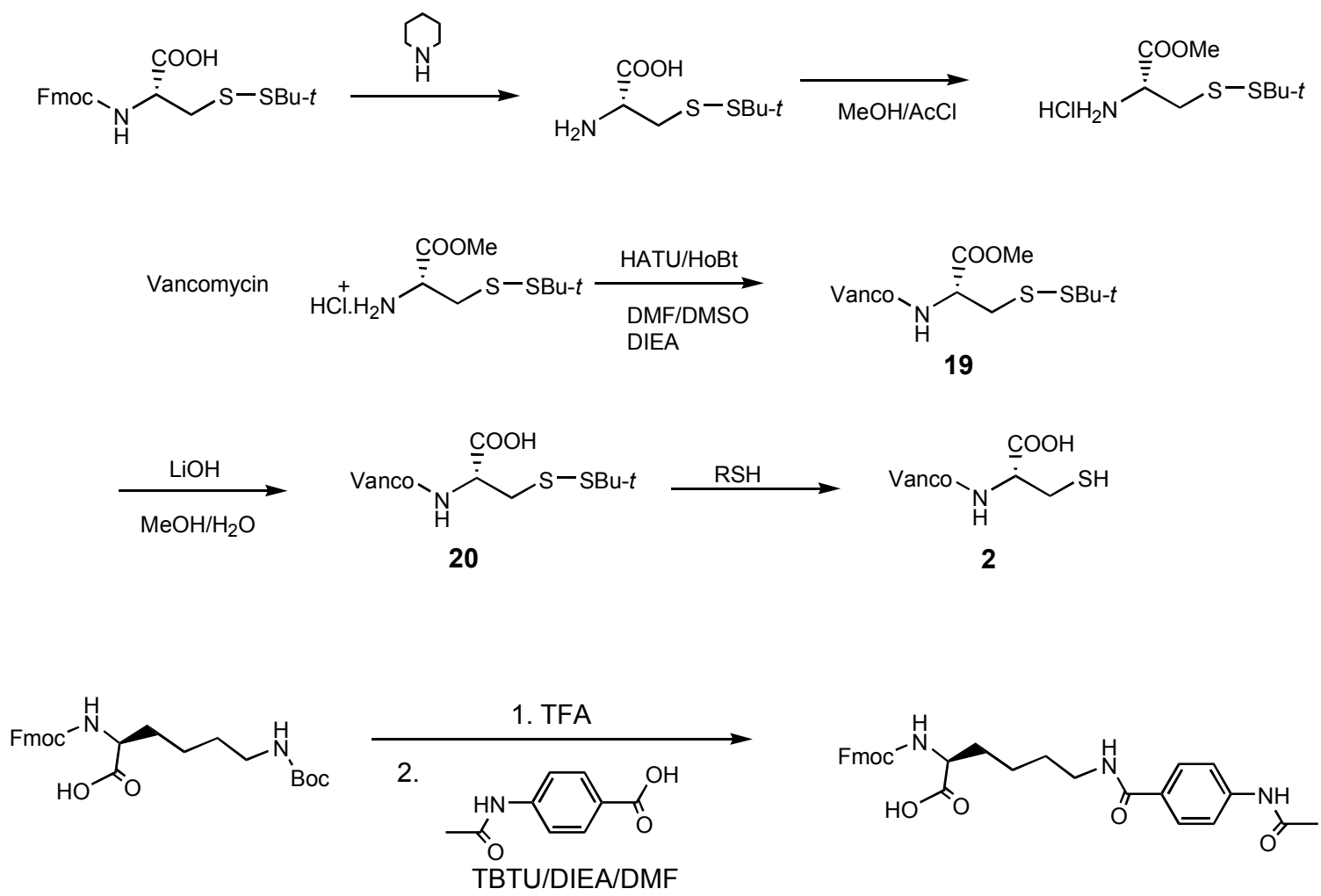

Preparation of compound 19. Vancomycin (150mg) was dissolved in DMSO (1.5 mL), HATU (38 mg), HOBT (15mg) and DIEA (50mg) was added, after $30 \mathrm{~min}$. the methyl, 3-[(1,1-dimethylethyl)dithio]L-alanate (30 mg, ) in DMF (1 mL) was added. The mixture was stirred and stayed overnight. The solvent was removed and the residue was purified on a C18 semi-prep column (Higgins Analytical) eluting with a water/acetonitrile/TFA gradient, lyophilized and give compound $19150 \mathrm{mg}$ in $89 \%$. Molecular weight was verified using a Bruker Esquire ESI calcd.1655, found (1655).

Preparation of Compound 20 Compound (17 mg ) was dissolved in the THF/water $(2 \mathrm{~mL})$ and lithium hydroxide $(1.2 \mathrm{mg})$ was added, after $30 \mathrm{~min}$. The reaction mixture was purified on a C18 semi-prep column (Higgins Analytical) eluting with a 
water/acetonitrile/TFA gradient, and lyophilized, give compound $2012.9 \mathrm{mg}$ in $77 \%$. Molecular weight was verified using a Bruker Esquire ESI calcd. 1641, found $\mathrm{M}^{+}(1641)$. Preparation of compound 2 Compound 20 (24mg) was dissolved in the PBS buffer, triethyl amine $(15 \mathrm{mg})$, ethyl thiol $(20 \mathrm{mg})$ was added the reaction was monitored by HPLC with absorbance at $270 \mathrm{~nm}$. After the reaction was complete, the reaction mixture was purified on a C18 semi-prep column (Higgins Analytical) eluting with a water/acetonitrile/TFA gradient, and lyophilized give compound $212 \mathrm{mg}$ in 53\% Molecular weight was verified using a Bruker Esquire ESI. cacld 1551, found $\mathrm{M}^{+}(1551)$ Maleimide-functionalized Magainin Peptide (9) Peptide synthesis was performed on Rink resin LS $(0.2 \mathrm{mmol} / \mathrm{g})$ using an Advanced Chemtech Apex Multiple Peptide Synthesizer, with diisopropyl carbodiimide (DIC) and N-hydroxybenzotriazole (HOBt) in $\mathrm{N}$-methylpyrrolidinone (NMP) for couplings, and 50\% piperidine in NMP for deprotection. The $\mathrm{N}$-Terminus of the original 23 residue magainin 2 peptide was capped with $\mathrm{XGGK}(\mathrm{ABA}), \mathrm{X}=\mathbf{7}$. Side chain protecting groups were Lys(Boc), His(Trt), Ser(But), Glu(OBut), Asn(Trt). Cleavage of the peptide was effected with a (94:2:2:2) TFA, triisopropylsilane, thioanisole and water mixture for $2 \mathrm{~h}$, resin was removed by filtration and peptides were precipitated with ether $(50 \mathrm{ml})$, centrifuged, and washed with ether (3_30 ml). Peptides were then dissolved in water and purified on a C18 semi-prep column (Higgins Analytical) eluting with a water/acetonitrile/TFA gradient, and lyophilized. Molecular weight was verified using a Bruker Esquire ESI or a Bruker Reflex III MALDI-TOF mass spectrometer.

Vancomycin-Cys-Magainin Conjugate (4) $9(10 \mathrm{mg})$ was dissolved in water (1 ml) and to this was added phosphate buffer $(1 \mathrm{ml}, 0.5 \mathrm{mM}, \mathrm{pH}=7.0)$, mixed with $2(5 \mathrm{mg}$, in $1 \mathrm{ml}$ 
phosphate buffer, $2.5 \mathrm{mM}, \mathrm{pH}=7.0$ ). Reaction was monitored by HPLC with an analytical C18 column (Higgins Analytical) by following UV absorbance at $230 \mathrm{~nm}$, and the product was purified with a semi-prep C18 column (Higgins Analytical). Collected fractions were lyophilized and gave 4. Molecular weight was verified with MALDI-TOF mass spectrometer. MALDI-TOF of 4, M.W. 4559 amu (see Figure S11).

\section{References for Scheme 3}

1. Metallo, S. J.; Kane, R. S.; Holmlin, R. E.; Whitesides, G. M., Journal of the American Chemical Society 2003, 125, (15),4534-4540

2. Sundram, U. N.; Griffin, J. H., Journal of Organic Chemistry 1995, 60, (5), 1102-3

3. Nicolaou, K. C.; Mitchell, H. J.; Jain, Nareshkumar F.; Winssinger, N,; Hughes, R.; Bando, T., Angewandte Chemie, International Edition 1999, 38, (1/2), 240-244

4. Videnov, G.; Stoev, S.; Brandenburg, D., Biological Chemistry Hoppe-Seyler 1989, $370,(10), 1103-11$

\section{B. FUSION ASSAYS}

Liposome Preparation Large unilamellar liposomes were prepared by the extrusion method. For a typical solution of labeled liposomes with Kaa-PE modification, a lipidic film containing (95:1.5:1.5:2) molar ratio of Egg PC, NBD-PE, Rh-DHPE and Kaa-PE was made by evaporation of the chloroform solution under nitrogen flow, and dried under reduced pressure overnight. The film was hydrated with Tris buffer (10 mM Tris, 100 $\mathrm{mM} \mathrm{NaCl}, \mathrm{pH}=7.4)$, and extruded 10 times both ways through a polycarbonate filter with $100 \mathrm{~nm}$ pore size. The final total lipid concentration was $2.5 \mathrm{mM}$.

Fusion Assay (Dye Dilution) Fusion was followed at $25^{\circ} \mathrm{C}$ in $3.5 \mathrm{ml}$ quartz cuvettes in a Perkin Elmer LS-50B fluorimeter (excitation $470 \mathrm{~nm}$, slit width $10 \mathrm{~nm} / 10 \mathrm{~nm}$, cutoff filter $515 \mathrm{~nm}$ ). For the 1:1 ratio (blank to labeled) fluorophore dilution assay, the "blank"

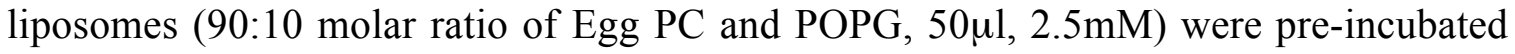
with 4 (93.6ul, $13.36 \mathrm{mM}, 1: 100$ molar ratio to the total lipid in "blank" liposomes) for 
10 minutes, diluted with Tris buffer $(1806.4 \mu 1,10 \mathrm{mM}$ Tris, $100 \mathrm{mM} \mathrm{NaCl}, \mathrm{pH}=7.4)$, and then added the fluorophore labeled liposomes with 3 modification $(50 \mu 1,2.5 \mathrm{mM})$. Fluorescence emission from $515 \mathrm{~nm}$ to $620 \mathrm{~nm}$ was followed immediately after mixing

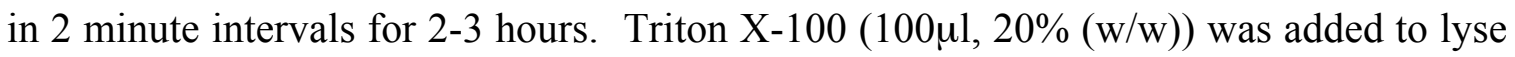
the liposomes, giving the maximum values of NBD fluorescence.

Reduction of NBD on the Outer Monolayer of Liposomes Liposomes with (96.5:1.5:2) molar ratio of Egg PC, NBD-PE and 3 (5mM total lipid concentration) were reduced by mixing with an equal volume of sodium dithionite solution $(100 \mathrm{mM}$ $\mathrm{Na}_{2} \mathrm{~S}_{2} \mathrm{O}_{4}, 10 \mathrm{mM} \mathrm{NaCl}$ ) in an ice bath for about 30 minutes until the NBD fluorescence was stable after a loss of $\sim 50 \%$ intensity. The mixture was then filtered through an exclusion gel column (Sephadex G-25, Sigma-Aldrich) to remove the excess dithionite. NBD fluorescence was measured before and after filtration to determine the final concentration of liposomes.

Fusion Assay (Inner Monolayer Lipid Mixing) Conditions were similar to the dye dilution assay. Liposomes containing 10\% POPG labeled with Rh-PE ( 88.5:10:1.5, Egg PC,POPG and Rh-PE, $50 \mu 1,2.5 \mathrm{mM})$ were incubated with $4(93.6 \mu 1,13.36 \mathrm{mM})$ for 10 minutes, diluted with Tris buffer $(1722 \mu 1,10 \mathrm{mM}$ Tris, $100 \mathrm{mM} \mathrm{NaCl}, \mathrm{pH}=7.4)$, and then NBD labeled, 3 modified liposomes were added(after reduction of the NBD fluorophore in the outer monolayer). Fluorescence was followed immediately after mixing for 2-3

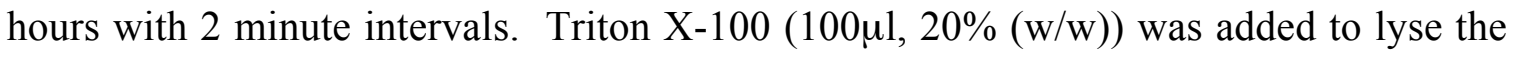
liposomes, giving the maximum values of NBD fluorescence. 


\section{DYNAMIC LIGHT SCATTERING}

Dynamic light scattering measurements were performed on a Brookhaven Instruments 200SM laser light scattering goniometer using a He-Ne $125 \mathrm{~mW} 633 \mathrm{~nm}$ laser. The vesicle dispersions are placed into glass tubes. Single scans with 2 minute averaging time were performed on the sample with a 90 degree angle, using liposome solutions prepared under the same conditions as fluorescence measurements were done, in absence of fluorophores. Results were reproducible within 3 repetitions. All measurements were taken immediately after mixing.

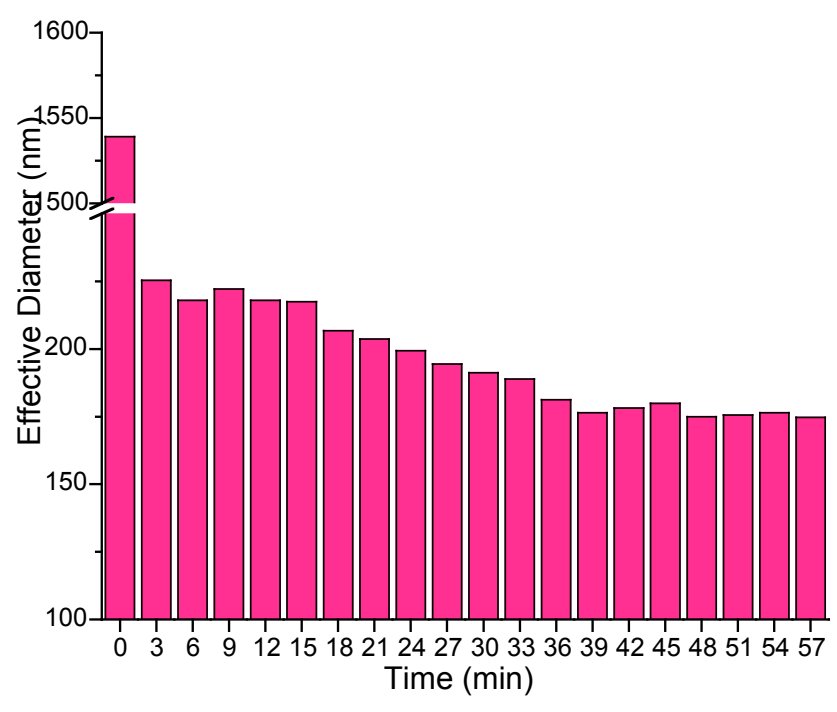

Fig S1. Representative trace of size change as a function of mixing time on liposomes surface functionized with $\mathbf{3}$ and $\mathbf{4}$. Vesicles with 2 mole percent $\mathbf{3}$ in egg PC were reacted with liposomes composed of 10 mole \% POPG in egg PC pretreated with 1 mole $\% 4$. 


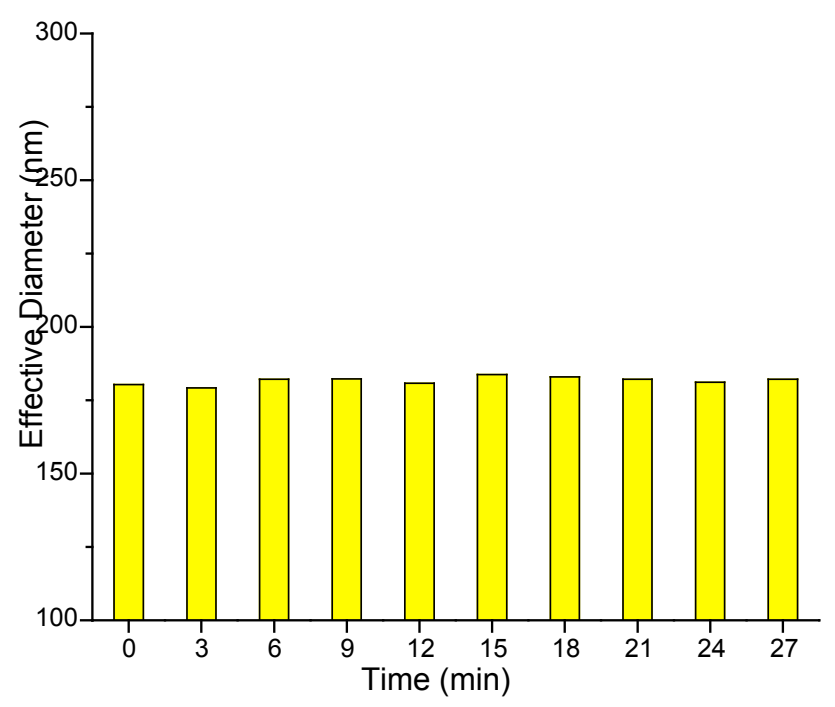

Fig S2. Free vancomycin inhibits fusion. Representative trace of scattering change as a function of mixing time. Vesicles with 2 mole \% 3 in egg PC, pretreated with 5 equivalents of free vancomycin were reacted with liposomes composed of 10 mole \% POPG in egg PC pretreated with 1 mole \% 4.

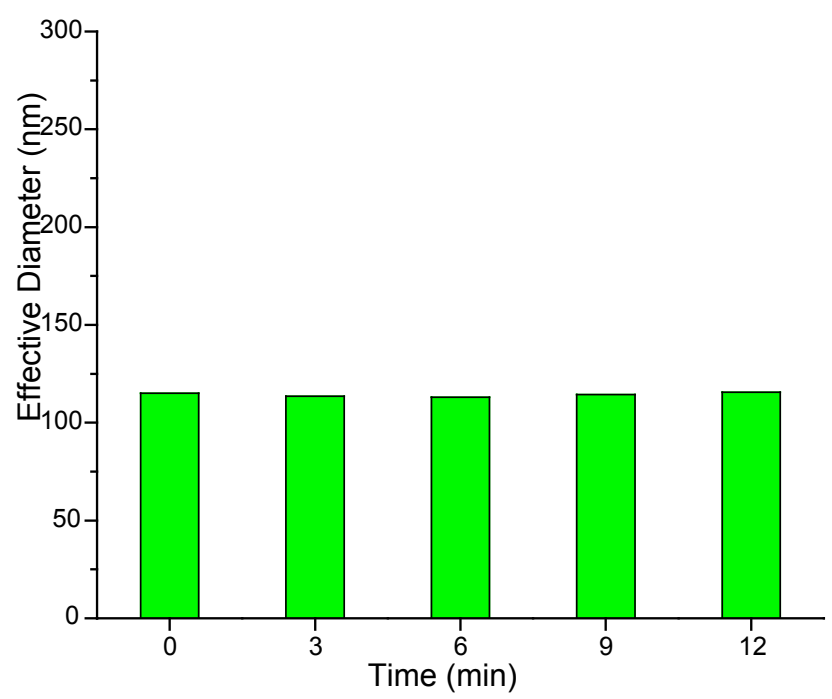

Fig S3. DLS of liposomes with 2 mole $\% 3$ in egg PC. 


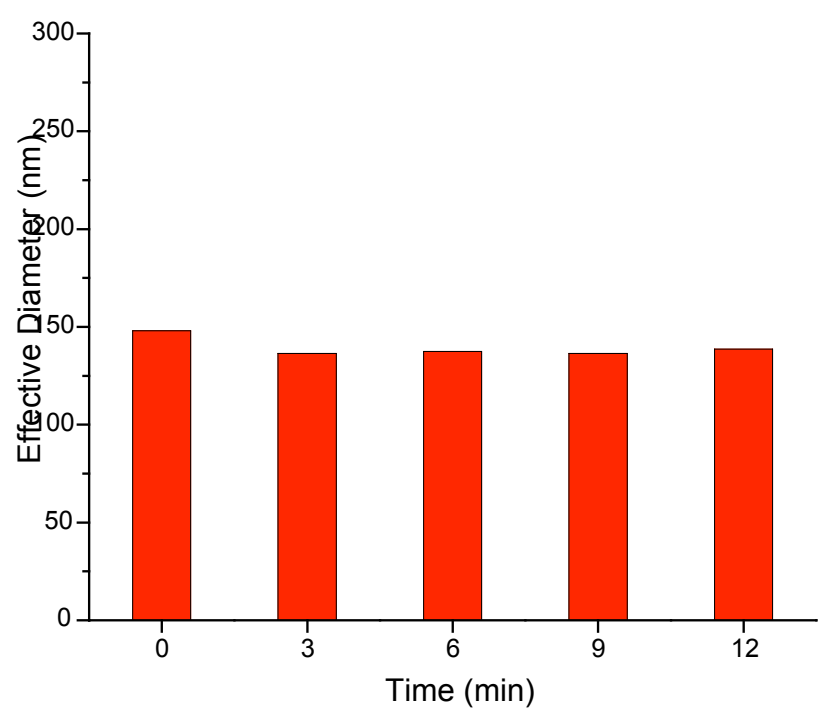

Fig S4. DLS of liposomes composed of 10 mole \% POPG in egg PC.

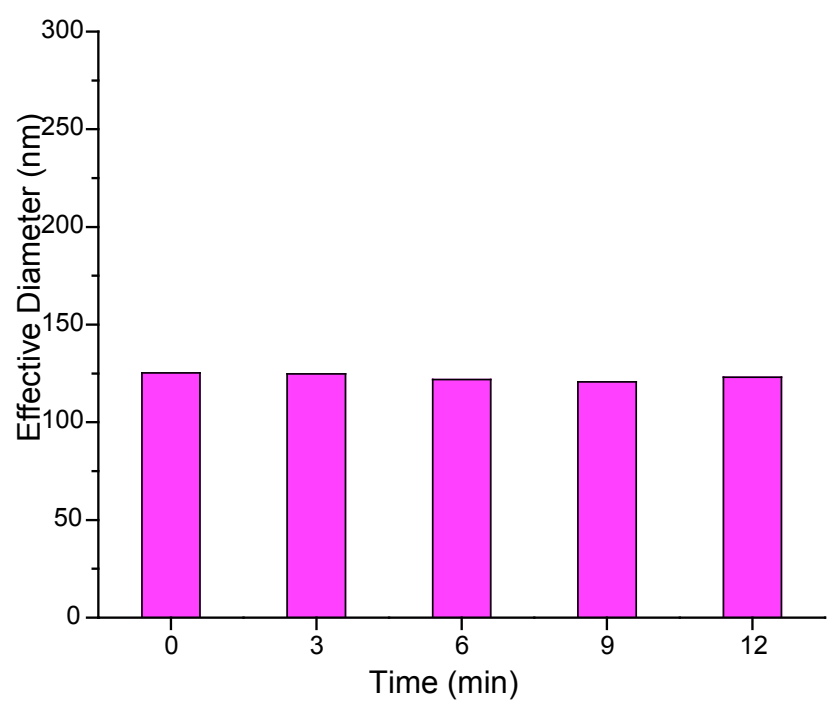

Fig S5. DLS of liposomes composed of 10 mole \% POPG in egg PC, mixed with vesicles with 2 mole $\% 3$ in egg PC. 


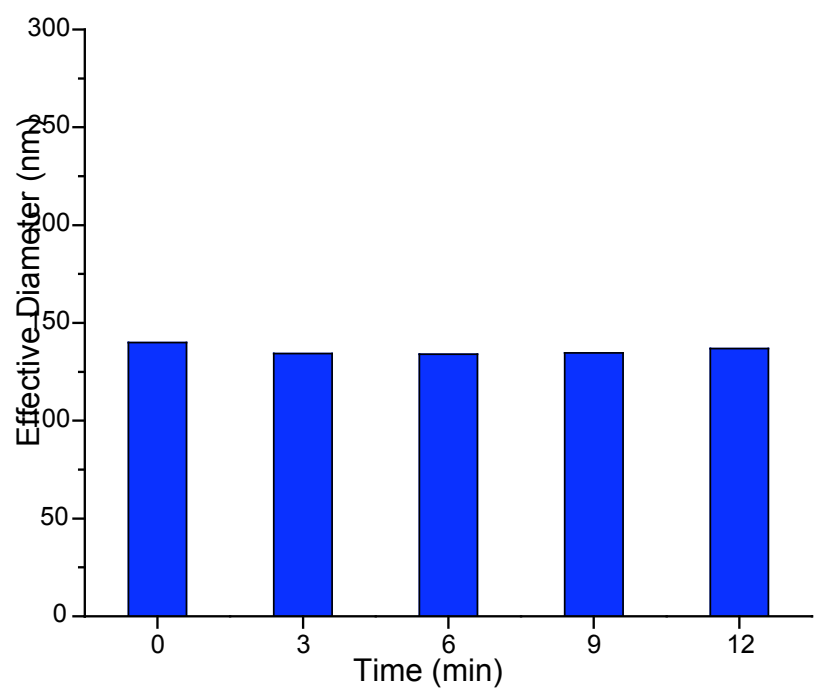

Fig S6. DLS of liposomes composed of 10 mole \% POPG in egg PC, mixed with 1 mole $\%$ 4. Measurements were taken immediately after mixing.

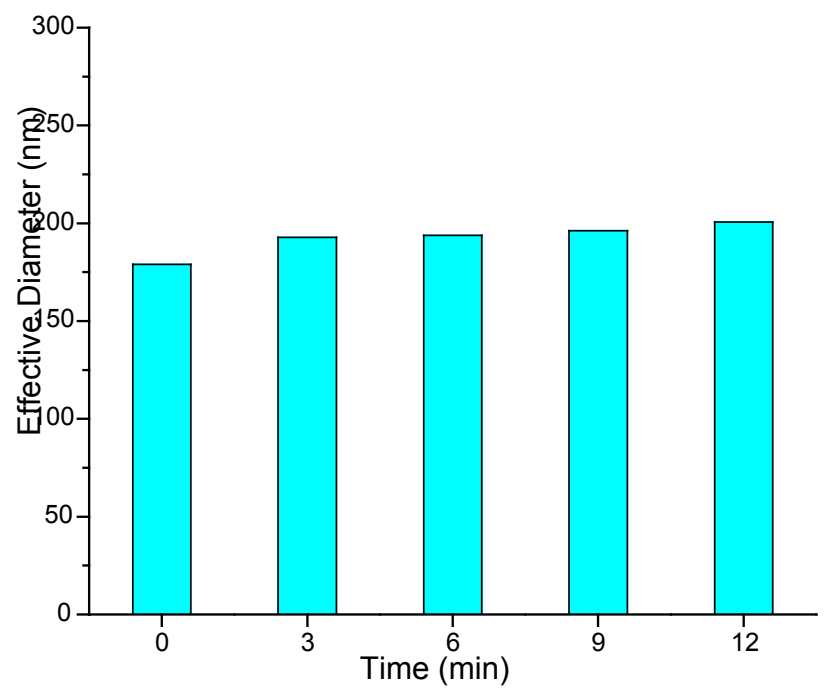

Fig S7. DLS of vesicles with 2 mole $\% 3$ in egg PC mixed with 1 mole $\%$ of 4 . Measurements were taken immediately after mixing. Moderate increase in size upon mixing, but no change through time as observed with fusion experiment. 


\section{SPECTRA}

\section{Mass Spectroscopy}

Electrospray mass spectroscopy was performed on a Bruker Esquire LC/MS plus ion trap spectrometer( Bruker-Daltonics, Boston, MA, USA) eqipped with an electrospray ionization source was employed for mass detection. The electrospray was operated in positive ion mode to produce mainly protonated molecular mass ions $(\mathrm{M}+\mathrm{H})+1$.

MALDI-Mass spectra were acquired on an Bruker Reflex III MALDI-TOF instrument. The peptide samples were dissolved in $0.1 \% \mathrm{v} / \mathrm{v}$ TFA in $50 \% \mathrm{v} / \mathrm{v}$ aqueous ACN. The aliquot $(1 \mu \mathrm{L})$ was spotted on a steel MALDI target plate (Bruker Daltonics) and $1 \mu \mathrm{L}$ of $\alpha$-cyanocinnamic acid (saturated in $\mathrm{ACN} / \mathrm{H}_{2} \mathrm{O} 1: 1 \mathrm{v} / \mathrm{v}$ ) solution used as the MALDI matrix.

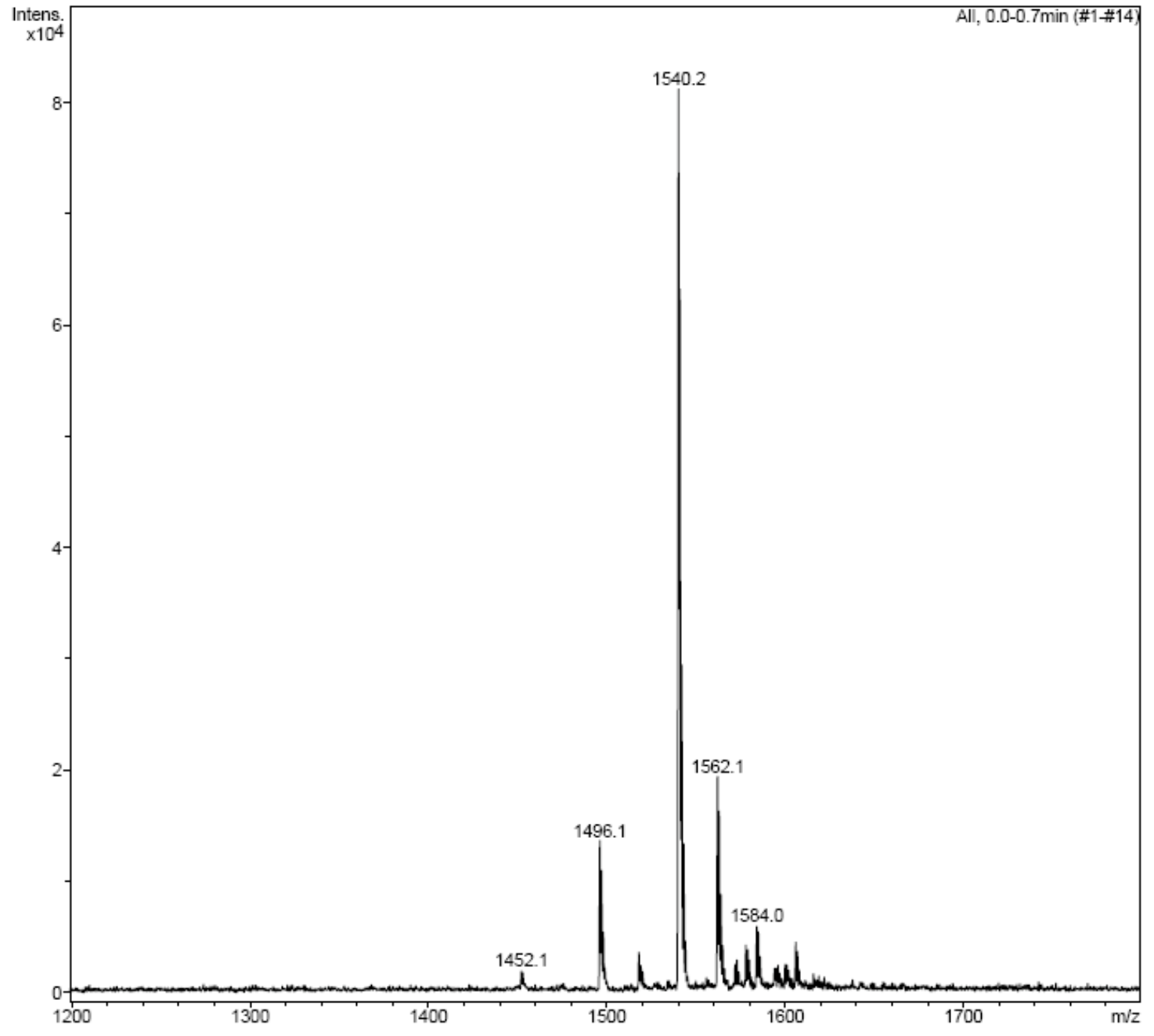

Figure S8. ESI of 3, mw= 1539 amu 


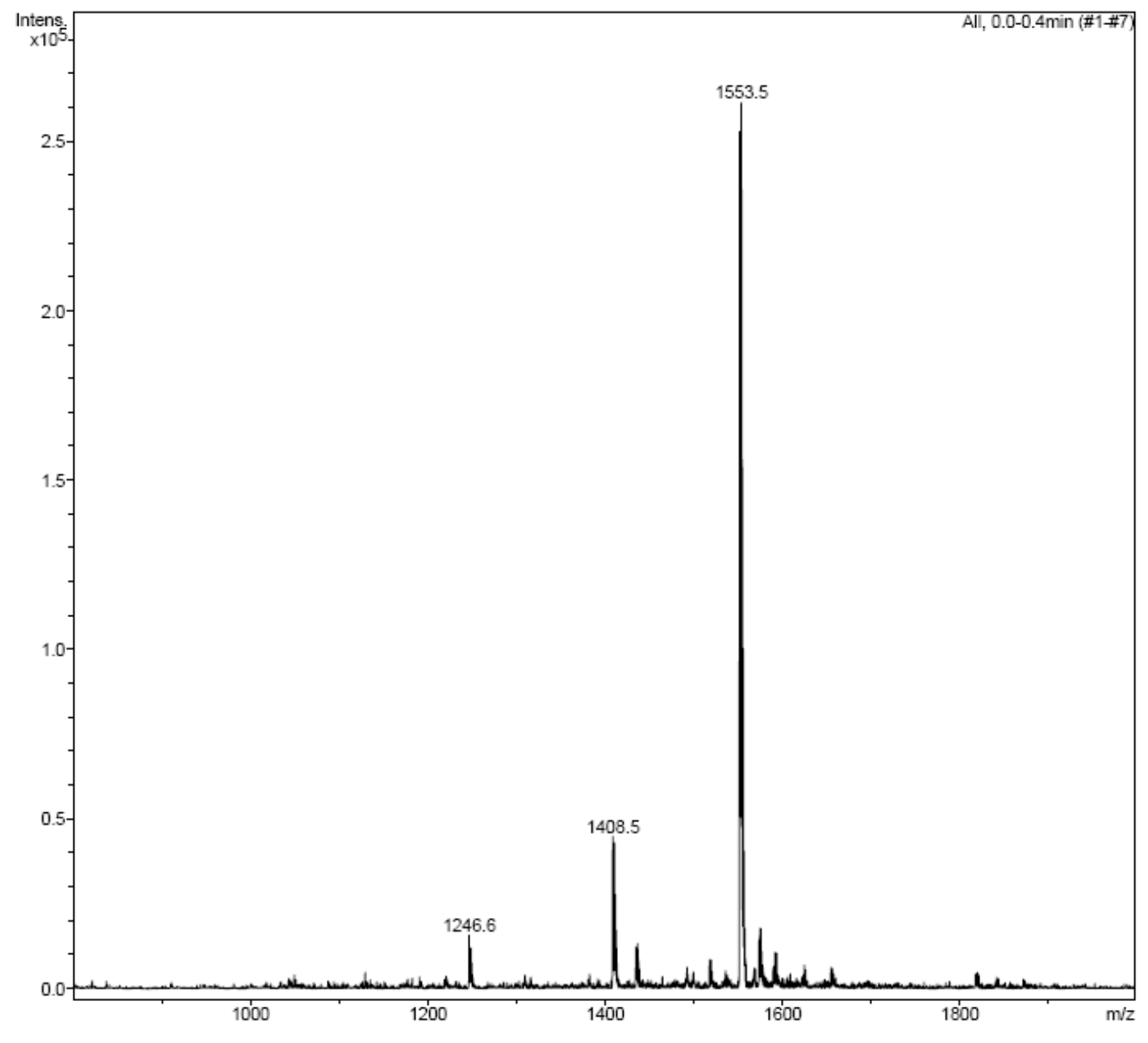

Figure S9. ESI of 2, mw $=1553 \mathrm{amu}$ 


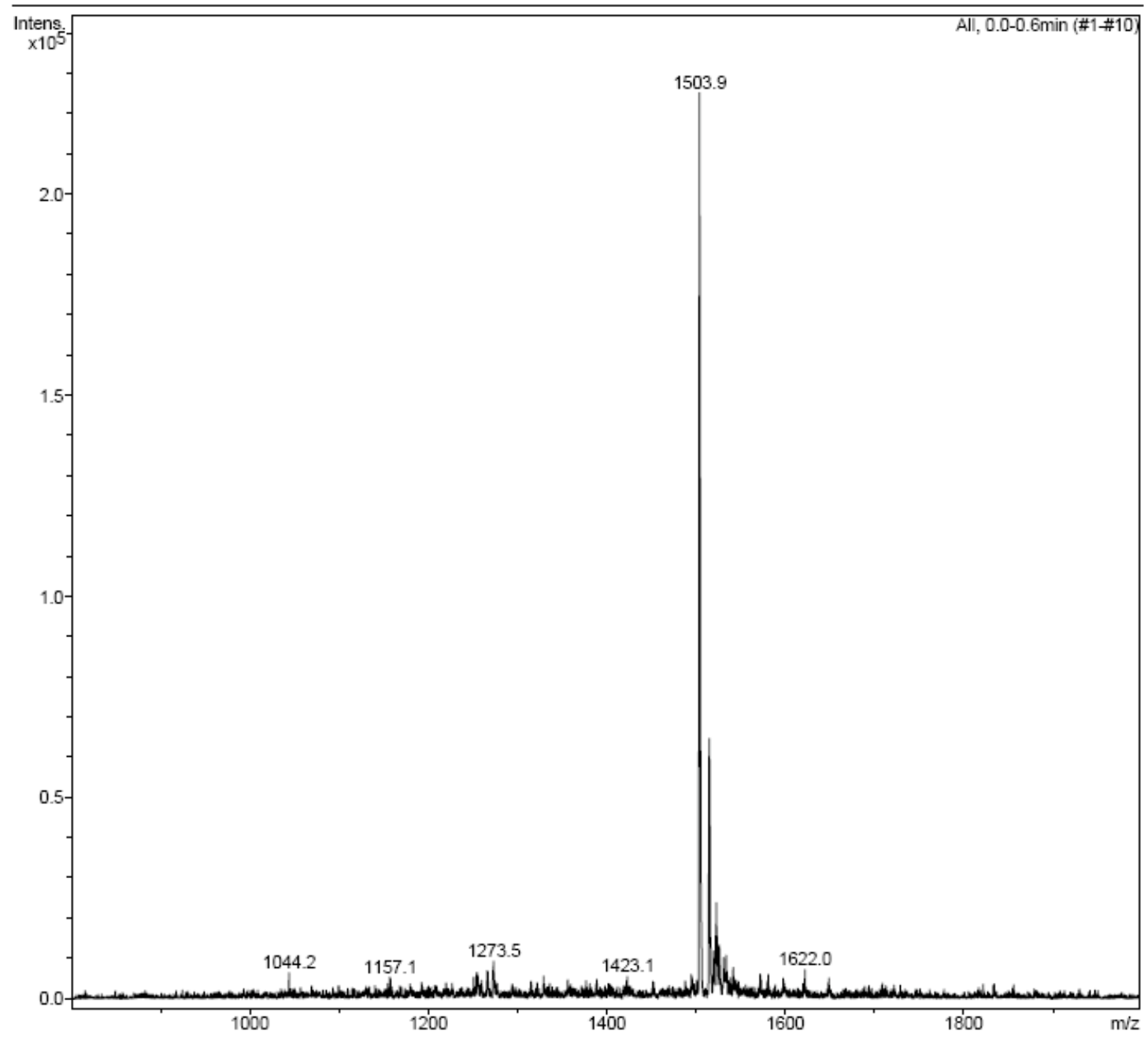

Figure S10. ESI of 9, mw=. $3004 \mathrm{amu}$ 


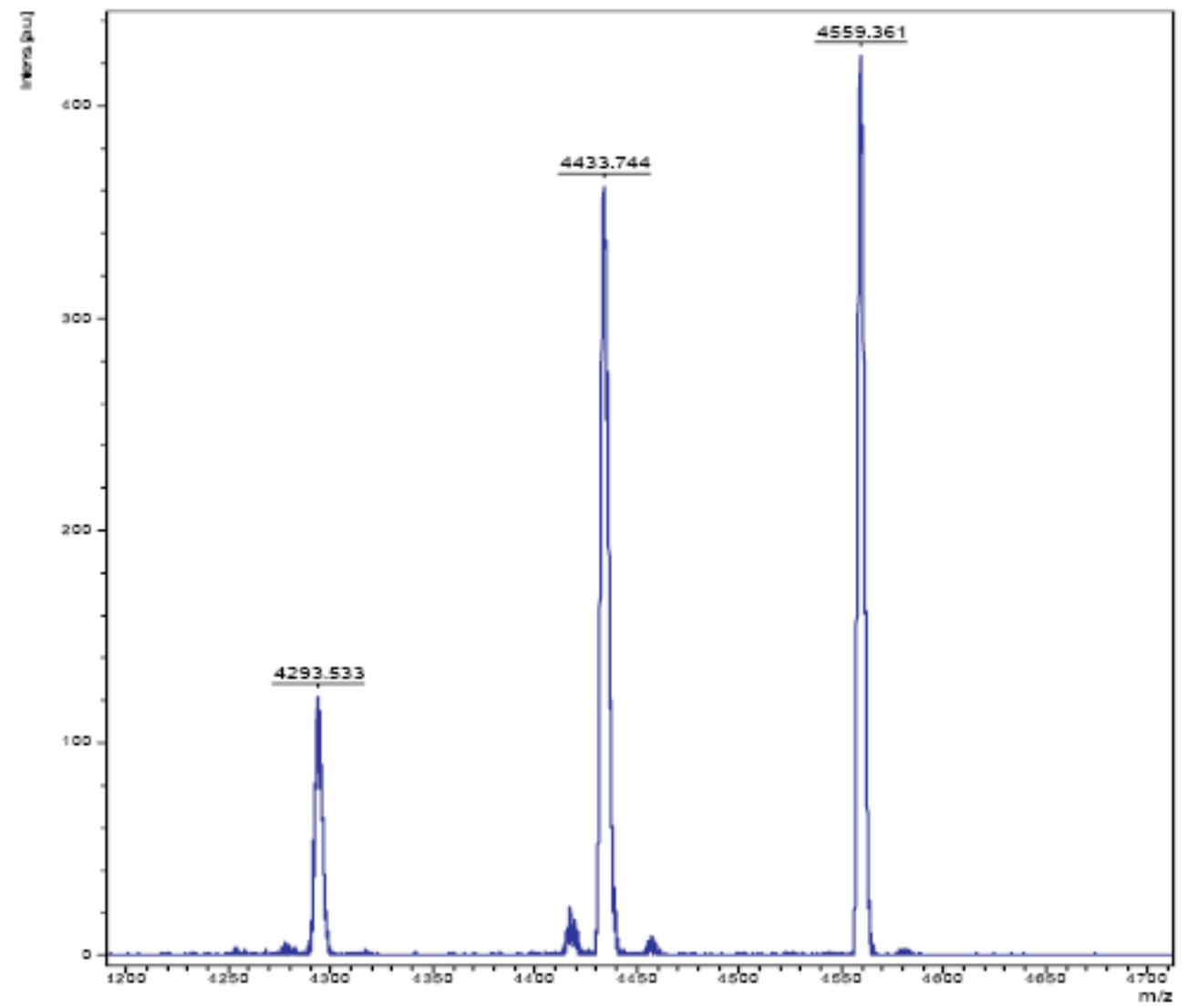

Figure S11. MALDI-TOF of 4, M.W. 4559 amu (Mass 4433.744 and 4293.523 are due to the loss of sugars in the molecule) 